\title{
The role of physical activity in the elderly as primary prevention
}

\author{
Michael Sagiv
}

Published online: 25 July 2007

(C) EGREPA 2007

Aerobic fitness in the older population is related to health status [5], all-cause mortality [9], and functional capacity $[5,9,13,14]$. Stathokostas et al. [16] described longitudinal (10 years) decline in aerobic fitness-maximal oxygen uptake and submaximal aerobic power (ventilatory threshold) in a relatively large sample of men and women, aged 55-85 years, living independently in the community [16]. Ten years after initial testing, 62 subjects ( 34 men, mean age $73.5 \pm 6.4$ years; 28 women, $72.1 \pm 5.3$ years) achieved maximal oxygen uptake. The men showed a rate of decline of $-0.43 \mathrm{ml} \cdot \mathrm{kg}^{-1} \cdot \mathrm{min}^{-1} \cdot \mathrm{year}^{-1}$, and the decline in maximal oxygen uptake was consequent to a lowered maximal heart rate with no change in the maximum oxygen pulse. The women showed a slower rate of decline of maximal oxygen uptake of $-0.19 \mathrm{ml} \cdot \mathrm{kg}^{-1} \cdot \mathrm{min}^{-1} \cdot$ year $^{-1}$, again with a lowered maximal heart rate and unchanged oxygen pulse.

Evidence for the role of the muscles themselves in the reduction of maximal oxygen uptake is muscle atrophy [15] and the reduction in oxidative properties with age [7]. Recent in vivo measurements of whole muscle by magnetic resonance indicate a significant age-related decline in oxidative properties per muscle volume [3]. These in vivo whole muscle determinations point to a significant loss of muscle oxidative capacity that, combined with the observed reduction in muscle mass, may account for the reduction in maximal oxygen uptake with age.

Physical activity is one of the most important and effective ways to prevent and treat certain health problems in older adults. During physical activity, the body is using energy to move muscles. Exercise is a type of physical

\section{Sagiv $(\square)$}

Life Science Department,

Zinman College of Physical Education and Sport Sciences, Wingate 42902, Israel

e-mail: sagiv@wincol.ac.il activity that is designed to improve fitness. The importance of physical activity as a tool to reduce the risk of various chronic degeneration diseases in the elderly has been conclusively established in recent years. In 1992, the American Heart Association stated that regular aerobic physical activity plays a primary role in the prevention of cardiovascular disease [4]. However, as early as in the 1950 s, the connection between a sedentary lifestyle and the onset of coronary artery disease with time was noted [10]. While addressing two different occupation populations, which differ mainly by their physical activity required at work, Morris and Heady [10, 11] demonstrated that the physically active population had less incidence of coronary artery disease compared to the sedentary population.

In agreement with the above findings [10, 11], two decades later, Paffenbarger et al. [12] illustrated the same phenomenon. In a 22-year follow-up of 3,686 San Francisco longshoremen, a cohort analysis assessed job activity (via energy expenditure) and risk factors for heart disease, morbidity, and mortality. The risk factors include cigarette smoking, blood pressure, blood cholesterol level, obesity, and glucose metabolism in relation to fatal heart attack. The study demonstrated an inverse relationship between energy expenditure and fatal heart attack, which was most evident in younger and middle-aged cohorts compared to aged subjects. Furthermore, the role of energy expenditure was still manifested when viewed against the influence of the other risk factors [8]. Along with the increased evidence associating lower level of physical activity with higher risk of death from heart disease [6, 18], data from longitudinal studies have emerged indicating the influence of physical activity on longevity and mortality from other chronic disease such as cancer, diabetes, hypertension, and osteoporosis [17]. In addition, regular physical exercise is the best antidote to many of the effects 
of aging. Major benefits from regular exercise include the following: favorable effects on fats in the blood, better handling of blood sugar, improved breathing, better endurance, improved balance, greater strength, stronger bones, improved sense of well-being, and better sleep. Studies are currently being done to determine the benefits of exercise programs for increasing life expectancy and decreasing the risk of or delaying disability as long as possible.

Physical activity is an important constituent of physical fitness. Moreover, fitness level can be true a marker of regular physical activity [6]. Physical fitness for the aged is composed of various components, such as cardiorespiratory fitness, body composition, muscle mass and strength, aerobic endurance, and flexibility. These variables and their adaptive response to regular physical activity result in an enhanced fitness level. Thus, a high level of physical activity, as measured via physical fitness level, may delay all-cause mortality, primarily due to lowered rates of cardiovascular disease and cancer. Blair et al. [1] found in 13,344 participants that the highly fit subjects at the highest level of either blood pressure or cholesterol had a lower risk of death than unfit subjects with low blood pressure or cholesterol level. However, fitness level alone is not the only indicator of future risk of coronary artery disease. Fitness level is comprised of both genetic predisposition and habitual physical activity [6]. Being highly fit yet inactive does not provide any protection against coronary artery disease. Furthermore, unfit though active men have a lower risk of coronary artery disease than unfit but sedentary men [6]. Hence, physical activity is the key to enhanced health status, rather than the fitness level by itself.

In particular, the present status of physical activity should be considered as a tool for primary prevention of chronic diseases. Williams [18] and, more recently, Chiuve et al. [2] have shown that men who improved their physical fitness level reduced their mortality risk. Consequently, only the current activity level is associated with a lower rate of death from all causes and from coronary artery disease. This is the main principle in the reviews by Sagiv, "Alterations in IGF-I affect elderly: role of physical activity", Ben-Sira, "Physical activity in aging and risk factors: primary prevention", and Melendez, "Osteoporosis, falls and exercise" appearing in this issue. They discuss the importance of the role of exercise training in the aged as a primary prevention tool of chronic degeneration. In addition, they address the topic of the recommended amount of physical activity required for health promotion, along with providing current exercise guidelines.

Another way to integrate exercise into health care is to view it in the light of its potential to reduce risk factors for chronic diseases. The very large potential for exercise to act as a primary prevention tool is obvious from the kinds of risk factors and diseases listed. The major causes of morbidity and mortality (heart disease, stroke, diabetes, cancer, arthritis, functional dependency, hip fracture, and dementia) in the older population are all more prevalent in individuals who are sedentary compared to more active peers.

\section{References}

1. Blair SN, Kohl HW 3rd, Paffenbarger RS Jr, Clark DG, Cooper KH, Gibbons LW (1989) Physical fitness and all-cause mortality. A prospective study of healthy men and women. JAMA 262:2395-2401

2. Chiuve SE, McCullough ML, Sacks FM, Rimm EB (2006) Healthy lifestyle factors in the primary prevention of coronary heart disease among men: benefits among users and nonusers of lipid-lowering and antihypertensive medications. Circulation 114:160-167

3. Conley KE, Jubrias SA, Esselman PE (2000) Oxidative capacity and ageing in human muscle. J Physiol 526:203-210

4. Fletcher GF, Blair SN, Blumenthal J (1992) Statement on exercise. Benefits and recommendations for physical activity programs for all Americans. A statement for health professionals by the Committee on Exercise and Cardiac Rehabilitation of the Council on Clinical Cardiology, American Heart Association. Circulation 86:340-344

5. Frontera WR, Hughes VA, Fielding RA, Fiatarone MA, Evans WJ, Roubenoff R (2000) Aging of skeletal muscle: a 12-yr longitudinal study. J Appl Physiol 88:1321-1326

6. Hein HO, Suadicani P, Gyntelberg F (1992) Physical fitness or physical activity as a predictor of ischaemic heart disease? A 17-year follow-up in the Copenhagen Male Study. J Intern Med 232:471-479

7. Houmard JA, Weidner ML, Gavigan KE, Tyndall GL, Hickey MS, Alshami A (1998) Fiber type and citrate synthase activity in the human gastrocnemius and vastus lateralis with aging. J Appl Physiol 85:1337-1341

8. Menotti A, Lanti M, Nedeljkovic S, Nissinen A, Kafatos A, Kromhout D (2006) The relationship of age, blood pressure, serum cholesterol and smoking habits with the risk of typical and atypical coronary heart disease death in the European cohorts of the Seven Countries Study. Int J Cardiol 106:157-163

9. Morey MC, Pieper CF, Cononi-Huntley J (1998) Physical fitness and functional limitations in community-dwelling older adults. Med Sci Sports Exerc 30:715-723

10. Morris JN, Heady JA, Raffle PA, Roberts CG (1953) Coronary heart-disease and physical activity of work. Lancet 265:1111-1120

11. Morris JN, Raffle PA (1954) Coronary heart disease in transport workers; a progress report. Br J Ind Med 11:260-264

12. Paffenbarger RS Jr, Hale WE, Brand RJ, Hyde RT (1977) Workenergy level, personal characteristics, and fatal heart attack: a birth-cohort effect. Am J Epidemiol 105:200-213

13. Paffenbarger RJ, Hyde RT, Wing AL, Hsieh C (1986) Physical activity, all cause mortality, and longevity of college alumni. N Engl J Med 314:605-613

14. Paterson DH, Govindasamy D, Vidmar M, Cunningham DA, Koval JJ (2007) Longitudinal study of determinants of dependence in an elderly population. J Am Geriatr Soc (in press)

15. Proctor DN, Joyner MJ (1997) Skeletal muscle mass and the reduction of $\mathrm{V}_{\mathrm{O} \text { max }}$ in trained older subjects. J Appl Physiol 82:1411-1415

16. Stathokostas L, Jacob-Johnson S, Petrella RJ, Paterson DH (2004) Longitudinal changes in aerobic power in older men and women. J Appl Physiol 97:781-789

17. Steffen LM, Arnett DK, Blackburn H (2006) Population trends in leisure-time physical activity: Minnesota Heart Survey, 1980 2000. Med Sci Sports Exerc 38:1716-1723

18. Williams PT (2003) The illusion of improved physical fitness and reduced mortality. Med Sci Sports Exerc 35:736-740 